\title{
O Sentido Político das Relações entre Educação e Autonomia e suas Diferentes Implicações
}

\author{
Glaurea Nádia Borges de Oliveira \\ Departamento de Educação da Educação Física da Universidade do Estado da Bahia, Guanambi, BA - Brasil. \\ gnoliveira@uneb.br
}

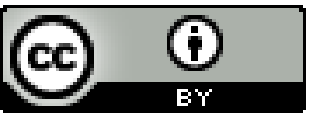

Educação: teoria e prática, Rio Claro, SP, Brasil - elSSN: 1981-8106

Está licenciada sob Licença Creative Common

\section{Resumo}

A educação, enquanto um processo social e uma prática política, pode assumir diferentes perspectivas e significações, atuando contra ou a favor de determinados modelos e valores. Partindo dessa premissa, este artigo procura tecer uma análise crítica acerca da apropriação do conceito de autonomia pelo discurso educacional vigente, na tentativa de esclarecer a significação política dessa apropriação e suas consequentes implicações em relação às diversas dimensões do processo educativo. Tal análise, construída a partir de uma reflexão teórica empreendida durante a concretização de uma pesquisa cujo foco incidia sobre a relação entre a prática educativa e a autonomia, permite constatar que, conquanto a autonomia possa estar sendo sujeitada a uma instrumentalização que reduz o seu verdadeiro significado e a coloca a serviço do ideário neoliberal, sua legitimidade ainda pode e deve ser garantida no âmbito educacional. Essa legitimidade implica o entendimento da autonomia de forma articulada aos fatores sociais, culturais, políticos, econômicos e ideológicos que condicionam a experiência dos sujeitos e das instituições, com vistas à construção de relações sociais mais justas e igualitárias.

Palavras-chave: Autonomia. Dimensões políticas da educação. Discurso educacional. Prática educativa.

\section{The Political Meaning of Relations between Education and Autonomy and their Different Implications}

\begin{abstract}
The education, as a social process and a political practice, can take different perspectives and meanings, acting for or against certain models and values. From this premise, this paper makes a critical analysis about appropriation of the autonomy concept by the current educational discourse, in an attempt to clarify the political meaning of this appropriation ant its consequent implications for various dimensions of the educational process. This analysis
\end{abstract}


shows that, although the autonomy may be being subjected to an instrumentalization that reduces its true meaning and puts it in the service of neoliberal conception, its legitimacy still can and should be ensured in the context of education. This legitimacy requires the autonomy be understood in connection to the social, cultural, political, economic and ideological factors that condition the individuals and institutions experience, towards the construction of social relations fairer and more egalitarian.

Keywords: Autonomy. Political dimensions of the education. Educational discourse. Educational practice.

\section{Introdução}

Este trabalho é fruto de uma reflexão teórica empreendida durante a concretização de uma pesquisa cujo foco incidia sobre a relação entre a prática educativa e a autonomia ${ }^{1}$. Portanto, a discussão apresentada se constrói com base no diálogo crítico com a literatura e no entendimento que os resultados dessa pesquisa permitiram alcançar.

Inicialmente, é preciso deixar claro que as análises que aqui se fazem sustentam-se na ideia de que a educação é, inevitavelmente, uma prática política. E, embora essa afirmação possa estar, como pontua Charlot (1979, p. 13), prestes a se tornar uma "banalidade pedagógica", ela merece ser reiterada e discutida, pois ainda subsistem muitas tentativas de reivindicar a neutralidade política da educação, ocultando-se as relações entre escola e sociedade, como se tal posicionamento pudesse também deixar de ser um ato político.

Além disso, e como também evidencia Charlot (1979), não basta afirmar que a educação é política, sem se esclarecer o que isso, de fato, significa, ou de que formas a significação política da educação se manifesta. Essa é a tarefa que se assume nesta discussão, particularmente no que concerne aos sentidos, explícitos e implícitos, assumidos pelo conceito de autonomia quando ele é associado às questões educacionais.

Há de se reconhecer, também, que a significação política da educação, seja no que diz respeito à autonomia ou a qualquer outro aspecto, não se expressa apenas de uma maneira ou em um âmbito específico. A educação é um fenômeno complexo e, como tal, é configurada por diferentes estruturas que se inter-relacionam. Ou seja, discutir a educação pode significar referir-se às políticas educacionais mais amplas, às organizações dos sistemas

\footnotetext{
${ }^{1}$ Esta pesquisa se refere à minha dissertação de mestrado, defendida em 2011 no Programa de Pós-Graduação em Educação: Psicologia da Educação da Pontifícia Universidade Católica de São Paulo.
} 
de ensino em esferas mais localizadas, às instituições escolares ou às relações entre professores e alunos.

O âmbito mais global, que corresponde às políticas públicas educacionais e à definição de regras, parâmetros, objetivos e condições que norteiam os processos educativos que se realizam em um determinado contexto, talvez seja aquele em que o caráter político da educação fique mais evidente. Mas isso não quer dizer que tal caráter se limite a esse domínio. A educação é política em todas as suas dimensões e, nesse sentido, cabe-nos questionar de que maneiras isso se concretiza, desde a definição de políticas públicas e de leis que as implementam até o cotidiano das instituições escolares. Afinal, nas discussões sobre educação, não basta permanecer nas relações mais amplas entre escola e sociedade, é preciso fazer com que essas relações alcancem um nível mais específico, que explicite o como a dimensão social opera no dia-a-dia dos estabelecimentos de ensino e de seus atores.

A busca de respostas a esse questionamento, por outro lado, carrega em si o desafio de que as análises não percam de vista a perspectiva de totalidade, que insere as práticas educativas institucionalizadas no processo social mais abrangente que as constituem, sem a qual uma visão verdadeiramente crítica e aprofundada acerca dos vínculos indissociáveis entre educação e sociedade tornar-se-ia impraticável.

\section{A educação como prática política}

Afirmar que a educação é uma prática política significa, sobretudo, reconhecer que existe uma íntima relação entre educação e sociedade, entre o processo educacional e a realidade social em que ele se efetiva. Esse vínculo se explica pelo fato de que a escola, enquanto uma instituição social, tanto é determinada pelos fatores que constituem a sociedade quanto atua sobre ela, por meio de sua função socializadora dos sujeitos.

Uma análise crítica dessa relação permite-nos evidenciar que ela ocorre sob duas perspectivas opostas. A educação, como uma prática política, de um lado atua de forma conservadora, reproduzindo integralmente a estrutura social vigente, representada pelos valores e pelas relações de poder do mundo capitalista; por outro lado, a atuação educacional pode assumir uma função transformadora e progressista, desmascarando os interesses dominantes e gerando uma nova consciência entre os cidadãos. 
Severino (2001, p. 72), ao abordar o caráter político da educação a partir da sua função reprodutiva e transformadora, esclarece que, no primeiro caso, "a educação contribui para a conservação da sociedade ao reproduzir seus conteúdos ideológicos". Nesse sentido, o aparelho escolar atua para manter as relações sociais típicas da sociedade capitalista, reforçando os seus mecanismos de dominação. De modo contrário, prossegue o autor, a educação pode tornar-se uma prática a favor da transformação, ao "[...] criticar e superar esses conteúdos ideológicos e assim atuar na resistência à dominação da sociedade, contribuindo para [a construção de] relações político-sociais menos opressoras" (SEVERINO, 2001, p. 75).

Além dos pontos de vista fomentados por meio de conteúdos ideológicos, a contribuição do sistema educacional para a reprodução da ordem social hegemônica é, também, caracterizada pela distribuição regulada do capital cultural (BRINHOSA, 2003).

Por conseguinte, o pressuposto central que norteia esta reflexão é o de que em todas as dimensões (das instâncias normatizadoras às relações pedagógicas) e em todos os aspectos (dos quais aqui se toma como foco de discussão a temática da autonomia) dos processos educativos, a significação política da educação pode se manifestar sob uma dessas duas perspectivas, conquanto se deva reconhecer - como o fazem Freire (2009) e Mogilka (2003), por exemplo - que elas não se manifestam de forma exclusiva. Ainda que, no contexto educacional brasileiro, seja possível admitir a prevalência da função reprodutiva da educação, essa função não é exercida de modo único e linear, pois a escola não apenas reproduz a ideologia dominante e as estruturas sociais; ela é influenciada por essas estruturas, mas os sujeitos da prática educativa são potencialmente capazes de influenciálas.

\section{O sentido político das relações entre educação e autonomia}

A própria definição do conceito de autonomia, a depender da perspectiva teórica que a fundamenta, pode expressar diferentes visões sobre o homem, a sociedade e o papel da educação. Contudo, uma discussão mais aprofundada a respeito das bases teóricoconceituais desse construto, embora se faça necessária, escapa às intenções e aos limites deste trabalho. 
Em linhas gerais, a autonomia pode ser entendida como a capacidade, faculdade ou direito (do indivíduo, de um grupo, de uma instituição, de uma entidade etc.) de se autogovernar, de tomar decisões próprias e de agir livremente, sem interferências externas. E, para os propósitos aqui elencados, o aspecto mais importante a se ressaltar é que, tradicionalmente, a visão predominante acerca da autonomia tende a se orientar por uma concepção individualista e subjetivista, que a define de modo genérico e abstrato, sem vínculos com as condições sociais concretas em que se constrói. Essa visão decorre da própria formulação do conceito de autonomia pelo pensamento filosófico moderno em relação à moralidade humana - que o compreende como um atributo da vontade e da razão - e, ao ser apropriada e ressignificada pelo discurso educacional vigente, ela acaba produzindo alguns equívocos, especialmente no que se refere à autonomia do sujeito e ao seu estabelecimento como um ideal da formação educativa.

Sob uma perspectiva crítica, em contrapartida, argumenta-se que a capacidade de tomar decisões por si próprio, de agir em função dessas decisões e de se responsabilizar pelas suas ações precisa ser entendida de forma articulada aos condicionantes sociais, políticos, econômicos e culturais, pois é num contexto historicamente situado que os sujeitos e as instituições constituem a sua autonomia, o que somente lhes será possível por meio da conscientização sobre esses fatores condicionantes, a partir da qual poderão buscar a sua superação.

Essas possíveis e diferentes maneiras de se entender a autonomia resultam em algumas implicações para a educação e estão, por sua vez, relacionadas ao seu caráter político reprodutivo ou transformador. Certamente, essas relações não são lineares, tampouco facilmente identificáveis, mas um esforço crítico de interpretação permite-nos desvelar alguns de seus elementos.

O tema da autonomia tem ocupado, nos últimos tempos, um lugar expressivo no discurso educacional, sobretudo nos documentos oficiais que normatizam e orientam os processos educativos institucionalizados. Como pontua Barbosa (2008), não há reforma educativa que não se vincule à autonomia, como princípio e como objetivo, de modo que é possível afirmar que esse conceito parece ter se tornado um clichê nas discussões educacionais. 
A que se deve tamanho prestígio? Qual é o real significado atribuído à autonomia por esse discurso que a coloca como um dos fundamentos centrais da educação? O que significa defender e instituir a autonomia da escola pública, como o tem feito a nossa legislação educacional? Como tem se concretizado a autonomia dos professores, tão necessária ao pleno exercício da sua função? O que se quer dizer com a alegação de que a escola deve estar a serviço da construção da autonomia dos alunos?

A autonomia não é um conceito neutro. Por isso, precisamos nos interrogar sobre quais são os interesses que estão implícitos nas relações estabelecidas entre autonomia e educação, ou, em outras palavras, sobre qual é o sentido político dessas relações.

De acordo com o quadro aqui delineado, as respostas a esses questionamentos devem ser buscadas com base no entendimento de que o caráter político da educação, sendo esta uma prática estreita e necessariamente atrelada à realidade social, pode se manifestar sob duas perspectivas: reprodutiva ou transformadora. O sentido político das relações entre autonomia e educação, portanto, também corresponde a uma dessas duas perspectivas. Além disso, cada uma delas terá características e implicações específicas nas diferentes dimensões e em relação aos diferentes agentes do processo educativo. Ou seja, a temática da autonomia na educação, seja sob o ponto de vista da reprodução ou da transformação, está associada a determinados efeitos que incidem sobre a instituição escolar, sobre os professores e sobre os alunos. Analisemos mais detidamente cada um deles.

\section{A autonomia da escola, dos alunos e dos professores: reprodução ou transformação?}

Como desdobramento de uma função reprodutiva das relações sociais vigentes, a autonomia da escola pública, caracterizada pela descentralização do poder no sistema educacional e pela concessão de autonomia financeira, administrativa e pedagógica aos estabelecimentos de ensino, estaria, como se verifica na crítica de diversos autores, a serviço da desobrigação do Estado para com a educação pública. Brinhosa (2003, p. 40), por exemplo, analisa essa questão a partir da noção de que "as políticas sociais implementadas na sociedade brasileira [...] possuem o vínculo econômico, social e político com as políticas estruturadas e definidas pelas relações sociais e internacionais de produção". Logo, o lugar 
ocupado pela autonomia da instituição escolar na política educacional brasileira, enquanto política de um determinado setor da sociedade, deve ser interpretado em correlação com as atuais condições e interesses do modo de produção capitalista. Nesse sentido, a autonomia da escola pública insere-se no âmbito mais amplo de exigências da política econômica que rege a sociedade capitalista, que, entre outros aspectos, reivindica que o Estado seja afastado da sua função pública e tenha suas responsabilidades em relação às políticas sociais minimizadas, como uma condição para que ele exerça as novas funções que lhe são requeridas.

As iniciativas que promovem a autonomia da escola pública são também associadas ao risco de privatização do ensino como opção de política educacional. Além disso, e como mencionam Gadotti e Romão (1997), outra suspeita que se levanta em torno da autonomia escolar é a de que ela resulta na pulverização, na dispersão e no localismo, elementos que se constituem em obstáculos às ações reformistas e revolucionárias mais profundas e globais.

Outra dimensão sob a qual a autonomia é abordada nas discussões educacionais e nas diretrizes políticas contemporâneas da educação é aquela que a compreende como um ideal da formação educativa, em que se preconiza que a educação, por meio da intervenção pedagógica, deve contribuir para a formação da autonomia do aluno. Essa proposição, que, segundo Barbosa (2008), reconhece o poder pessoal do ser humano para intervir na configuração do seu próprio destino e que, nesse sentido, está associada à ideia de liberdade e de autorrealização, parece ser legítima, ao menos numa primeira apreciação. Entretanto, ela não emerge de modo abstrato, pois sempre esteve presente ao longo do percurso das ideias pedagógicas, percurso este que se construiu - e se constrói - em consonância com e em resposta às condições do contexto social moderno.

Assim sendo, Barbosa (2008, p. 459) argumenta que a valorização da autonomia e de estratégias pedagógicas que a incitem não pode ser analisada à margem do discurso neoliberal imperante, pois é justamente esse discurso que apela, insistentemente, à autonomia dos sujeitos, difundindo o que o autor denomina de "ideal normativo de indivíduo autônomo". Esse ideal, ao assentar-se no postulado de que a autonomia é sinônima de autossuficiência, fortalece a tendência de responsabilização das pessoas por todas as possibilidades e todos os limites que conformam a sua existência. Consequentemente, ele atua de modo estratégico, como álibi ideológico para que o Estado 
abdique de suas responsabilidades perante os cidadãos, além de servir como artifício para obrigar as pessoas a se controlarem a si mesmas, numa espécie de autonomia decretada.

A educação, ao defender e colocar em prática uma pedagogia que favoreça a formação da autonomia do aluno, pode estar exercendo sua função política de reprodução, a serviço desse ideário neoliberal, no qual a autonomia é sujeita a uma instrumentalização que reduz o seu verdadeiro significado e que, contraditoriamente, compromete e cerceia a liberdade humana.

Barbosa (2008) também chama a atenção para os efeitos - segundo ele, perversos a que uma pedagogia da autonomia ${ }^{2}$, ainda que com intenções humanistas, pode conduzir. Entre esses efeitos, destaca-se a suspeita de que a atuação pedagógica concernente com os supostos princípios da autonomia seja uma prática elitista, que favorece as classes dominantes em detrimento das classes econômica e socialmente desfavorecidas ${ }^{3}$. A principal justificativa para essa suspeição, explica o autor, é que esse tipo de proposta pedagógica baseia-se em formas de organização e de relação que não correspondem às estruturas e aos valores que predominam nas relações das famílias das classes populares e que são muito mais claras para as crianças que vivem em circunstâncias privilegiadas. É uma pedagogia que pressupõe uma imagem de criança que, na maioria das vezes, não reflete a dos filhos das classes baixas, tampouco as condições em que eles são criados.

O último foco desta análise acerca das relações entre educação e autonomia diz respeito à autonomia do professor. Aliás, essa é uma questão que, particularmente, se diferencia das dimensões anteriores, e não por acaso ela está sendo abordada por último.

Em primeiro lugar, a autonomia dos professores, em comparação à autonomia da escola e dos alunos, é a dimensão menos enfatizada pelas reformas educativas. Contrariamente a essas outras duas dimensões, nas quais a autonomia é apropriada e ressignificada pelas diretrizes educacionais, revelando sentidos velados a partir da sua valorização, parece que a autonomia do professor, em uma perspectiva reprodutiva da educação, manifesta-se sob uma lógica diferente. O que se observa, na verdade, são políticas que, implicitamente, restringem o poder de decisão e a autonomia do professor sobre o seu próprio trabalho.

\footnotetext{
${ }^{2}$ Aqui, a expressão pedagogia da autonomia não se refere ao livro escrito por Paulo Freire, que possui esse título.

${ }^{3}$ Esse tipo de crítica pode ser particularmente direcionado às propostas que se orientam pelos princípios construtivistas.
} 
O trabalho docente é rigidamente regulado pelo Estado, que, por meio de suas instâncias legisladoras, institui mecanismos de permissão e impedimento das ações dos professores. Esses mecanismos retiram-lhes a autonomia sobre o seu próprio ofício, colocando-os como meros executores de decisões tomadas de forma centralizada, geralmente sem a sua colaboração.

De modo agravante, a profissão docente é ainda afetada por uma séria contradição. Como claramente demonstra Roldão (2005), o poder de decisão sobre a ação desenvolvida é um dos atributos que garantem a uma função o estatuto de profissão plena e está, consequentemente, associado à responsabilização social e pública por essa ação. Os professores, entretanto, ao mesmo tempo em que são impedidos de decidir sobre o seu próprio trabalho, não deixam de ser responsabilizados pelo fracasso do sistema escolar público e pelo insucesso dos alunos, entendidos como resultantes de sua ação ineficiente. Se, na política educacional, a autonomia dos professores fosse tão preconizada e defendida como a autonomia da escola e a dos alunos, poder-se-ia concluir que ela estaria a serviço dessa responsabilização, que, em última instância, não deixa de corresponder à tendência neoliberal de responsabilização dos sujeitos, para a qual a autonomia serve de instrumento. Porém, a relação parece não ser exatamente essa, embora sejam necessários estudos mais minuciosos para se discutir e esclarecer essa questão. Ainda assim, nossa própria experiência no meio educacional permite-nos constatar que a autonomia docente não é um aspecto tão valorizado, o que se pode até mesmo interpretar como um recurso para que ela seja suprimida. De qualquer forma, esses elementos permanecem correlacionados à dinâmica das relações entre capital e trabalho, pois eles expressam a própria divisão social do trabalho, aqui caracterizada pela segmentação entre dirigentes e executores, em que alguns poucos especialistas detêm o poder de decisão e o controle, enquanto os professores e os demais profissionais da escola simplesmente executam aquilo que foi decidido e lhes é imposto pelas instâncias superiores do sistema educacional, e cujo sentido Ihes escapa quase completamente (GADOTTI; ROMÃO, 1997).

A questão é ainda mais complexa quando se verifica que esse processo contraria a própria autonomia da instituição escolar. Afinal, qual é o grau de autonomia possibilitado ou permitido à dimensão pedagógica e curricular? Como se pode conceber uma instituição escolar autônoma, se seus principais agentes são cerceados em relação ao seu trabalho? 
Talvez, isso possa ser explicado pelo que Brinhosa (2003) define como um novo tipo de estrutura de poder, que, conquanto proclame a descentralização das ações públicas do Estado, dispõe de mecanismos que protegem o seu monopólio da direção e mantêm um modelo piramidal e centralizador, ainda que menos autoritário. No entanto, essas são apenas especulações iniciais, que não nos permitem fazer afirmações generalizadas e que merecem ser aprofundadas por pesquisas futuras.

Diante de tantas críticas e suspeitas, é conveniente perguntar se ainda há lugar para a autonomia na educação. A resposta a essa pergunta deve ser positiva, exatamente porque se entende que a educação, apesar de reproduzir a ordem social hegemônica e de se apropriar de determinados conceitos, atribuindo-lhes significados que atendem aos interesses da ideologia dominante, pode, por outro lado, tornar-se um fator de mudança social, atuando com vistas à transformação dessa realidade historicamente construída. Sob uma perspectiva transformadora, o sentido político das relações entre autonomia e educação passa a ser outro, completamente oposto àquele fundamentado em lógicas que se apoderam do conceito de autonomia e o colocam a serviço da desumanização.

No que diz respeito ao estabelecimento de ensino, primeiramente, a autonomia está relacionada à possibilidade de que a escola construa o seu próprio projeto políticopedagógico, de acordo com os interesses, as necessidades e as características da comunidade em que ela está inserida e com a participação efetiva de todos os seus atores nos processos decisórios. Essa forma de planejamento e gestão não serviria à desobrigação do Estado perante sua função pública relativa à educação, tampouco conduziria a ações isoladas, ou a uma suposta e temida fragmentação do sistema educacional. Ao contrário, ela se assenta no princípio de parceria entre o governo e a escola e de comunicação entre várias unidades escolares. Desse modo, as políticas públicas educacionais devem ser o resultado das deliberações e iniciativas consolidadas no âmbito das instituições de ensino, num processo progressivo de formulação (GADOTTI; ROMÃO, 1997).

A autonomia escolar, de acordo com essa concepção, está ainda a favor da construção de uma escola realmente democrática, que respeite a diversidade sociocultural e que a todos beneficie, e que não reflita apenas o padrão cultural de um segmento minoritário da população, que vê na educação a estrutura e os valores ideais para a realização dos seus interesses. 
Esse projeto, no entanto, somente será viável se a escola se tornar um espaço que permita aos seus agentes a reflexão sobre os determinantes sociais que os condicionam e que os instrumentalize para que possam intervir sobre esses determinantes, buscando superá-los.

É nesse mesmo direcionamento que a prática transformadora da educação deve assumir a função de formar indivíduos autônomos. Autonomia não é autossuficiência. Autonomia é, ao contrário, conscientização ${ }^{4}$ e, nesse sentido, ela se opõe à alienação. Ser autônomo não é apenas deixar de ser afetado por condições externas, como se os diversos aspectos que constituem a vida humana - sucesso e fracasso, riqueza e pobreza, reconhecimento e discriminação, por exemplo - fossem alheios a tais condições e dependessem somente da intervenção do indivíduo na configuração do seu próprio destino. Ser autônomo é justamente tomar consciência desses fatores, inserindo-se criticamente na realidade. Essa é a noção que deve orientar o trabalho educativo e as relações pedagógicas que se queiram favorecedores da autonomia dos alunos. Esse é o sentido político transformador da autonomia na dimensão que a define como um ideal da formação educativa: o de que as ações pedagógicas, em todos os seus elementos e por mais corriqueiros que eles possam parecer, devem garantir aos educandos uma clara percepção da relação entre indivíduo e sociedade, oferecendo-lhes subsídios para que possam desvendar os vieses ideológicos dessa relação. Dito de outro modo, essas ações devem promover a conscientização dos alunos sobre o mundo do qual eles fazem parte, pois somente assim eles poderão, verdadeiramente, pensar e agir com autonomia.

Por fim, a autonomia docente é um fator imprescindível para que a autonomia da escola e a dos alunos se objetivem; é o elo que estrutura e fortalece as relações entre autonomia e educação numa perspectiva transformadora, mas é também, por outro lado, a dimensão mais enfraquecida dessas relações no atual contexto educacional.

Os professores são protagonistas do processo educativo, os principais agentes de uma necessária mudança, que, conquanto também dependa de outros atores, não se realizará sem a sua participação. A autonomia, por sua vez, implica conscientização e inserção crítica na realidade, elementos fundamentais à transformação e à emancipação

\footnotetext{
${ }^{4}$ A conscientização é aqui entendida segundo a definição desse construto pelo pensamento freireano. As relações entre autonomia e conscientização, estabelecidas a partir da análise do referencial freireano, são detalhadamente esclarecidas em minha dissertação de mestrado (OLIVEIRA, 2011).
} 
social. Portanto, não se pode conceber a autonomia da instituição escolar sem que os educadores tenham poder de decisão sobre o seu trabalho e esclarecimento crítico acerca do seu compromisso político. Ao mesmo tempo, a contribuição que se espera que os professores proporcionem, por meio da intervenção pedagógica, à construção da autonomia dos alunos, tanto dependerá da possibilidade que eles próprios tenham de se reconhecer como agentes políticos desse processo.

\section{Considerações finais}

As ideias apresentadas neste texto não têm a pretensão de esgotar a discussão acerca da apropriação do conceito de autonomia pelo discurso educacional, mas, sim, lançar luz sobre a necessidade de que essa apropriação seja criticamente analisada, procurando-se desvelar os seus significados, as suas nuances e as suas contradições.

Pode-se dizer que, atualmente, a autonomia é vítima de uma ambivalência: por um lado, ela é proclamada e defendida aos quatro ventos, adquirindo um prestígio talvez sem precedentes nas propostas e reformas educativas; por outro, ela é desacreditada, tanto em função da sua apropriação pelo discurso neoliberal, que distorce o seu verdadeiro significado, quanto pelas críticas que lhe são direcionadas pela pós-modernidade, que contesta a sua possibilidade de concretização. Nessa perspectiva, esta reflexão também assume a tarefa de tentar legitimar a autonomia sob a ótica de uma concepção de educação que luta pela transformação social. Este é o sentido que aqui se defende como possível e necessário para que a autonomia legitime o seu espaço nos processos educativos, embora se admita que ainda seja preciso um grande esforço, um movimento de luta contrário às tendências educacionais predominantes, para que ele de fato se concretize.

\section{Referências}

BARBOSA, Manuel Gonçalves. Do sonho ao pesadelo: a pedagogia da autonomia sob suspeita. Revista Brasileira de Estudos Pedagógicos, Brasília, v. 89, n. 223, p. 455-466, set./dez. 2008.

BRINHOSA, Mário César. A função social e pública da educação na sociedade contemporânea. In: LOMBARDI, José Claudinei (Org.). Globalização, pós-modernidade e educação: história, filosofia e temas transversais. 2. ed. Campinas: Autores Associados, 2003. p. 9-60. 
CHARLOT, Bernard. A mistificação pedagógica. Rio de Janeiro: Zahar Editores, 1979.

FREIRE, Paulo. Pedagogia da Autonomia. 39. ed. Rio de Janeiro: Paz e terra, 2009.

GADOTTI, Moacir; ROMÃO, José Eustáquio. Escola cidadã: a hora da sociedade. In: Cortez, 1997. p.43-50. (Orgs.). Autonomia da escola: princípios e propostas. São Paulo:

MOGILKA, Maurício. Educar para a democracia. Cadernos de Pesquisa, São Paulo, s/v, n. 119, p. 129-146, jul. 2003.

OLIVEIRA, Glaurea Nádia Borges de. Educação Física escolar e autonomia: a prática pedagógica sob a perspectiva freireana. 2011. 168 f. Dissertação (Mestrado em Educação: Psicologia da Educação) - Programa de Pós-Graduação em Educação: Psicologia da Educação, Pontifícia Universidade Católica de São Paulo, São Paulo, 2011.

ROLDÃO, Maria do Céu. Profissionalidade docente em análise - especificidades dos ensinos superior e não superior. Nuances: estudos sobre educação, Presidente Prudente, v. 12, n. 13, p. 105-126, jan./dez. 2005.

SEVERINO, Antônio Joaquim. Educação, sujeito e história. São Paulo: Olho d'Água, 2001. 